\title{
Preparation of a novel V2C mxene/g-C3N4 and its performance in plasma catalytic denitrification
}

\author{
Haoxuan $\mathrm{Hu}^{1}$, Ran $\mathrm{Zhao}^{1 *}$, Xianwei Fan ${ }^{1}$, Junyi Liu ${ }^{1}$, Yahui Nie ${ }^{1}$, and Dong Wang ${ }^{1 *}$ \\ ${ }^{1}$ Hubei Key Laboratory of Advanced Textile Materials \& Application, Hubei International Scientific and Technological Cooperation Base \\ of Intelligent Textile Materials \& Application, Wuhan Textile University, Wuhan 430200, China.
}

\begin{abstract}
In this work, the $\mathrm{g}-\mathrm{C}_{3} \mathrm{~N}_{4} / \mathrm{V}_{2} \mathrm{C}$ MXene composite catalyst was prepared by solvothermal method, and its denitration performance under synergistic plasma (NTP) was investigated. The results showed that when the mass ratio of $\mathrm{V}_{2} \mathrm{C}$ is $3 \%$, the denitration performance of $\mathrm{V}-\mathrm{CN}-3-\mathrm{NTP}$ is as high as $83.3 \%$, which is 1.2 and 2.1 times that of the $\mathrm{V}_{2} \mathrm{C}-\mathrm{NTP}$ and $\mathrm{g}_{-} \mathrm{C}_{3} \mathrm{~N}_{4}-\mathrm{NTP}$ systems alone. The apparent morphology, phase structure, and catalytic mechanism of the catalyst were studied by SEM, TEM, XRD, FTIR, XPS, etc. The results showed that $\mathrm{g}_{-} \mathrm{C}_{3} \mathrm{~N}_{4}$ grows well on $\mathrm{V}_{2} \mathrm{C}$ mxene. $\mathrm{V}_{2} \mathrm{C}$ is not only an electron acceptor but also an active site for $\mathrm{NO}$ adsorption. The electrons and holes generated by $\mathrm{V}_{2} \mathrm{C}$ could be effectively separated by the high-voltage electric field, which improves the denitration performance and shows a good synergistic effect.
\end{abstract}

\section{INRTODUCTION}

The exhaust gas emitted from human production and life has caused a lot of irreversible harm to the environment, and nitrogen oxides $\left(\mathrm{NO}_{\mathrm{x}}\right)$, as the most difficult part of exhaust gas treatment, has seriously affected people's daily life ${ }^{1}$. As a new type of gas pollutant treatment technology, plasma denitration technology improves the technical defects of traditional denitration process such as high energy consumption and high cost, and avoids the reducing agent required in SCR (selective catalytic reduction), and does not produce secondary pollution ${ }^{2}$, which is one of the most promising and effective technologies in the treatment of air pollution. During the discharge process, the breakdown gas generates high-energy electrons to provide energy for the reaction, thereby generating a series of reactive groups (such as $\mathrm{N}^{*}$ and $\mathrm{O}^{*}$ ), and these reactive groups react with $\mathrm{NO}$ gas molecules to form harmless substances. So far, plasma denitration technology still has some drawbacks (large power consumption, relatively low denitration efficiency, etc.). Therefore, in order to solve these problems, the denitration reaction with the catalysts-NTP synergistic method has become a hot research topic. Wang ${ }^{3}$ et al. reported a new type of $12 \mathrm{Mn}-12 \mathrm{Cu} / \mathrm{ZSM} 5$ catalyst in the plasma-catalyst system. The results showed that the combination of plasma and the catalyst improved the removal efficiency of $\mathrm{NO}$, and the introduction of $\mathrm{Mn}$ improved the performance of the $\mathrm{Cu} / \mathrm{ZSM} 5$ catalyst. $\mathrm{Yu}^{4}$ et al. divided the catalytic process of the plasma-assisted catalyst into two stages: in the first stage, $\mathrm{NO}_{\mathrm{x}}$ were adsorbed by the catalyst (not discharged); in the second stage, using $\mathrm{N}_{2}$ and $\mathrm{Ar}$ as carrier gas, the adsorbed $\mathrm{NO}_{\mathrm{x}}$ were decomposed into $\mathrm{N}_{2}$ And $\mathrm{O}_{2}$. The instantaneous increase of active oxygen groups was the main reason for improving the conversion of $\mathrm{NO}_{\mathrm{x}}$, and solid carbon was added as a trapping agent for active oxygen groups to increase the conversion rate of $\mathrm{NO}_{\mathrm{x}}$ in the $\mathrm{N}_{2}$ plasma. However, in order to improve the denitration efficiency, many researchers used metals as catalysts, which were too costly and may cause metal pollution. Most of the relative studies require the addition of reducing agents (such as $\mathrm{CH}_{4}$ and $\mathrm{NH}_{3}$ ) to the reaction system, which did not exert the synergistic effect of this kind of system. This work aimed to construct a cheap new plasma synergistic catalytic system to overcome these problems.

g- $\mathrm{C}_{3} \mathrm{~N}_{4}$ (graphite phase carbon nitride), as a non-metallic material, has attracted attention in the field of catalysis due to its suitable band gap ,easy synthesis, low cost, and good physical and chemical properties ${ }^{5}$. However, its lower carrier separation efficiency and smaller specific surface area limited its practical application in the field of catalysis. Therefore, researchers have made efforts to improve its performance defects, and through a series of methods (such as surface control $^{6}$, doping ${ }^{7}$ and formation of heterojunctions with semiconductors ${ }^{8}$ ), the separation efficiency and specific surface area of electrons and holes have been increased, and the specific surface area has been increased. The active sites on the surface further increased the activity of the catalyst ${ }^{9}$. The electrons of $\mathrm{g}-\mathrm{C}_{3} \mathrm{~N}_{4}$ was migrated by the high-voltage electric field, which improved its reduction performance and facilitated the reduction of $\mathrm{NO}^{10}$. In this work, a one-dimensional tubular g-C3N4 is prepared, which exposed more active sites under the support of a large specific surface area, thereby improving its denitration performance.

Transition metal carbides and nitrides (called MXenes)

*Corresponding authors. E-mail address:ranzhao.hust@gmail.com(R.zhao),wangdon08@126.com(D.Wang) 
are one of the latest 2D materials. Since Naguib et al ${ }^{11}$ first developed $\mathrm{Ti}_{3} \mathrm{C}_{2}$, they have promoted a lot of research, are widely used, and show excellent performance. In addition, the large specific surface area and abundant surface functions made MXenes effective adsorbents for various molecular and ionic species, expanding their applications in ion screening, catalysts and sensors ${ }^{12-14}$. Vanadium carbide $\left(\mathrm{V}_{2} \mathrm{C}\right)$ is a typical MXene material, which has similar properties to titanium carbide $\left(\mathrm{Ti}_{3} \mathrm{C}_{2}\right)$, has metal conductivity and hydrophilicity, and has excellent chemical stability and light stability ${ }^{15}$. Among them, good thermal stability is an important prerequisite for maintaining good properties in plasma ${ }^{16} \cdot \mathrm{V}_{2} \mathrm{C}$ was mostly used in energy storage and conversion, such as batteries, capacitors, etc ${ }^{17-19}$. But due to its excellent performance, it had a very broad prospect in catalysis. This article applies $\mathrm{V}_{2} \mathrm{C}$ to the field of catalysis for the first time, and uses it with $\mathrm{g}-\mathrm{C}_{3} \mathrm{~N}_{4}$ for denitration in the plasma-catalysts system .

In this work, the solvothermal method was used to grow $\mathrm{V}_{2} \mathrm{C}$ etched by $\mathrm{HF}$ on the dicyandiamide supramolecular precursor, and then calcined at high temperature to generate $\mathrm{V}_{2} \mathrm{C} / \mathrm{CN}$ composite. Under the action of the low-temperature plasma synergistic catalyst, the denitration performance of the $\mathrm{V}_{2} \mathrm{C} / \mathrm{CN}$ composite reaches up to $83.3 \%$, which is 2.1 and 1.2 times that of the CN-NTP system and the $\mathrm{V}_{2} \mathrm{C}$-NTP system alone. In addition, characterization techniques were used to study the properties of the catalyst, and the synergistic mechanism of $\mathrm{V}_{2} \mathrm{C} / \mathrm{CN}$ and NTP was studied.

\subsection{Synthesis of $\mathrm{V}_{2} \mathrm{C}$}

In an ice bath, $\mathrm{V}_{2} \mathrm{AlC}(1 \mathrm{~g})$ powder was slowly added to $20 \mathrm{~mL}$ of hydrofluoric acid (48\%) within 5 minutes and stirred the above mixture vigorously at $35^{\circ} \mathrm{C}$ for 24 hours, then increased the temperature to $50^{\circ} \mathrm{C}$ and continue stirring for 48 hours. The as-prepared suspension was then centrifuged, and the obtained solids were washed repeatedly with deionized water until the $\mathrm{pH}$ value is close to neutral $(>6)$, and then freeze-dry to obtain $\mathrm{V}_{2} \mathrm{C}$ MXene powder ${ }^{15}$.

\subsection{Synthesis of $\mathrm{V}_{2} \mathrm{C} / \mathrm{g}-\mathrm{C}_{3} \mathrm{~N}_{4}$}

$3 \mathrm{~g}$ of dicyandiamide (DCDA) was added to a mixed solvent consisting of deionized water and isopropanol (water/isopropanol volume ratio=1:2), and stirred for 30 min. Then a certain amount of $\mathrm{V}_{2} \mathrm{C}$ was added to the mixed solution and stirred, and then the obtained solution was transferred to a $25 \mathrm{~mL}$ autoclave and kept at $180^{\circ} \mathrm{C}$ for 10 hours. After the reaction was completed, the product was centrifuged to obtain a supramolecular precursor. Then, washed three times with water and ethanol to remove the remaining solvent, and then dried in a vacuum at $80^{\circ} \mathrm{C}$ overnight. Finally, the supramolecular precursor was heated to $550^{\circ} \mathrm{C}$ at a heating rate of $10^{\circ} \mathrm{C} / \mathrm{min}$, and stored in the air for 2 hours to generate a $\mathrm{g}-\mathrm{C}_{3} \mathrm{~N}_{4}(\mathrm{CN}) / \mathrm{V}_{2} \mathrm{C}$ sample. The final products were designated as $\mathrm{C} / \mathrm{V}-1, \mathrm{C} / \mathrm{V}-2, \mathrm{C} / \mathrm{V}-3$, and $\mathrm{C} / \mathrm{V}-4$, corresponding to the weight of $\mathrm{V}_{2} \mathrm{C}$ MXene to dicyandiamide $(1,2,3 \text {, and } 4 \mathrm{wt} \%)^{20}$.

\section{EXPERIMENTAL SECTION}

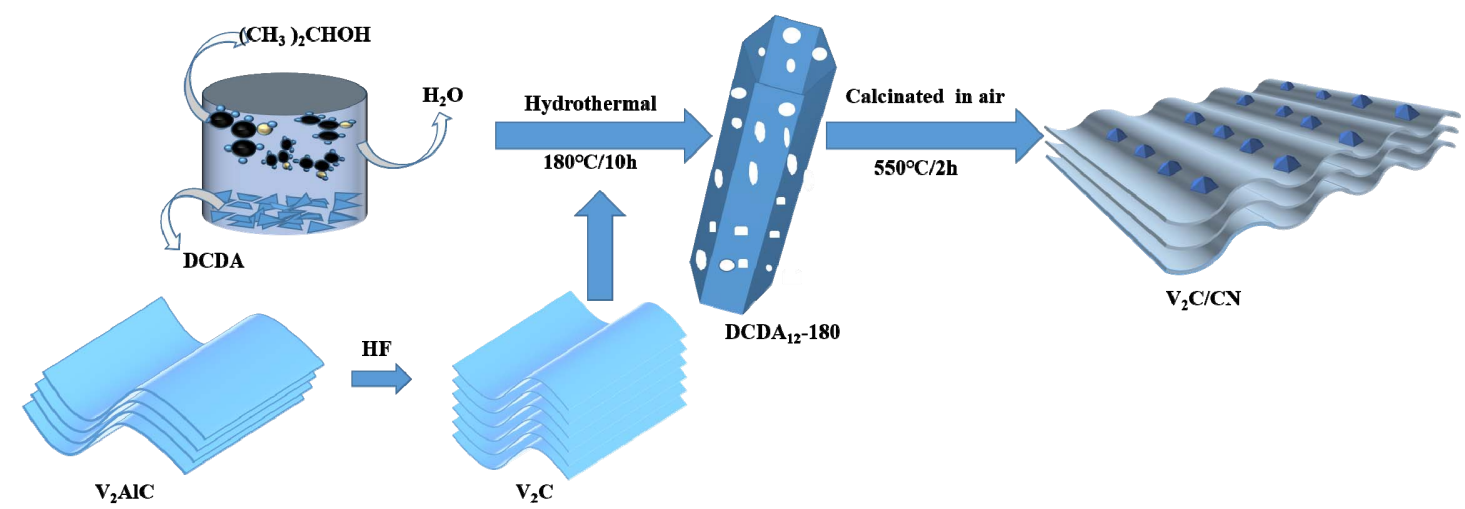

Scheme 1. Schematic Diagram of the Synthesis Process of the $\mathrm{V}_{2} \mathrm{C} / \mathrm{g}-\mathrm{C}_{3} \mathrm{~N}_{4}$ catalyst

Barrett-Joyner-Halenda

(BJH)

method.

\subsection{Characterization}

The crystal phase was determined by X-ray diffraction (XRD, Bruker D8 Advance, Germany, Cu K $\alpha$ ). The X-ray photoelectron spectra (XPS) of samples were collected by a spectrometer(Thermo Fischer , ESCALABXi+, Al-K $\alpha$ ). The morphologies of materials were characterized on a scanning electron microscope (SEM, JSM-IT300A), The Brunauer Emmett Teller surface area (BET) was obtained by $\mathrm{N}_{2}$ adsorption-desorption isotherms measured at $77 \mathrm{~K}$ on a surface area analyzer (Micromeritics, ASAP2460), and pore structural parameters were determined by the
Thermogravimetric analysis (TGA) was carried out using a NETZSCH STA 449F3 instrument under a nitrogen atmosphere.

\subsection{Experimental procedure and apparatus}




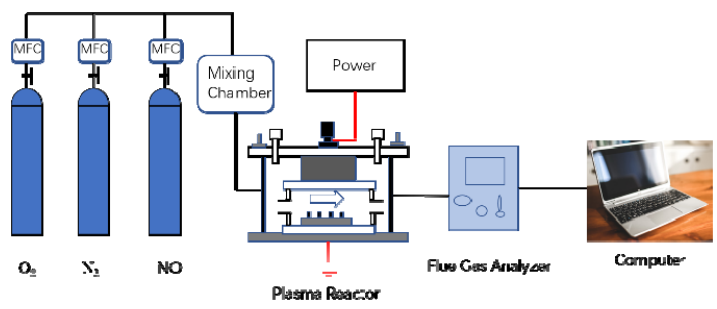

Fig. 1 Schematics of experimental apparatus.

The NO denitrification device consists of a gas generator, a dielectric barrier discharge (DBD) reactor, and a gas detection device (as shown in the Fig. 1). The simulated flue gas is composed of 500ppm NO, 8\% $\mathrm{O}_{2}$ and $\mathrm{N}_{2}$ balance gas. Use a flow controller (MFC) to control the gas flow at $500 \mathrm{~mL} / \mathrm{min}$. The experimental sample is $0.5 \mathrm{~g}$. The inlet and outlet $\mathrm{NO}$ and $\mathrm{NO}_{2}$ concentrations are analyzed online with KM950 flue gas analyzer. All tests are performed at atmospheric pressure and room temperature. The denitration efficiency is calculated as follows:

$$
\eta=\left(1-C / C_{0}\right) \times 100 \%
$$

where $\eta$ is the denitration rate $(\%), \mathrm{C}_{0}$ is the inlet NO concentration(ppm) and $\mathrm{C}$ is the outlet NO concentration (ppm).

The two stainless steel electrodes $(\varphi 50 \times 15 \mathrm{~mm})$ are high voltage electrodes and ground electrodes. The distance between the two electrodes is $10 \mathrm{~mm}$. The DBD $(\varphi 60 \times 8 \mathrm{~mm}, \mathrm{DBD}-100 \mathrm{~B}, \mathrm{Nanjing}$ Suman Electronics Co., Ltd., China) reactor made of quartz glass is placed between the two electrodes.

\section{RESULTS AND DISCUSSION}

\subsection{SEM}

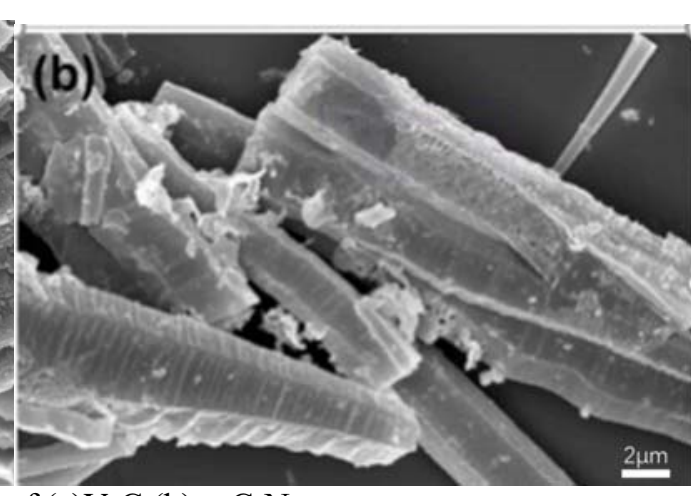

Fig. 2 SEM images of (a) $V_{2} C$; (b) $g-C_{3} N_{4}$

The morphology and microstructure of the prepared catalyst were analyzed by SEM. As shown in Fig. 2(a), the $\mathrm{V}_{2} \mathrm{AlC}$ precursor was etched in $\mathrm{HF}$ and freeze-dried in a liquid environment to obtain a good two-dimensional layered structure, and clearly depicted very thin two-dimensional flakes. Obviously, hydrothermal treatment transformed DCDA12-180 into a 1D hexagon. It's important to note that subsequent calcination of DCDA12-180 at $550^{\circ} \mathrm{C}$ produced $1 \mathrm{D}$ mesoporous $\mathrm{g}-\mathrm{C}_{3} \mathrm{~N}_{4}$ microtubes, retaining the $1 \mathrm{D}$ hexagonal microtubular morphology (Fig. 2b). Volume shrinkage occurred during high-temperature calcination, which could be attributed to the formation of a denser structure with a higher degree of polymerization.

\subsection{XRD}

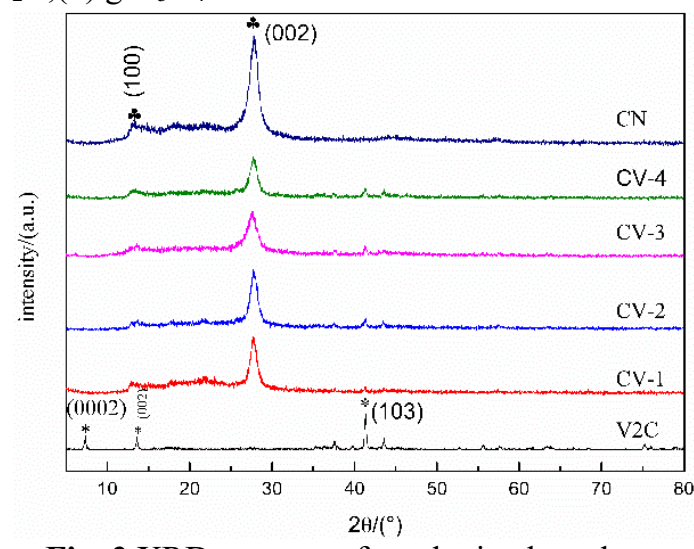

Fig. 3 XRD patterns of as-obtained catalysts

X-ray diffraction technology was used to analyze the phase and crystal structure of the catalyst. The analysis results are shown in Fig. 3, and the results confirmed the successful synthesis of $\mathrm{CN}, \mathrm{V}_{2} \mathrm{C}$ and $\mathrm{V}_{2} \mathrm{C} / \mathrm{CN}$ composite. Two main XRD peaks can be clearly found in the $\mathrm{V}_{2} \mathrm{C}$ spectrum, corresponding to approximately $13.6^{\circ}$ and $41.2^{\circ}$ respectively. And after HF etching, a new XRD peak appeared at about $7.1^{\circ}$, corresponding to the (0002) crystal plane of $\mathrm{V}_{2} \mathrm{C}$, indicating the successful synthesis of $\mathrm{V}_{2} \mathrm{C}^{15}$. There are two typical XRD peaks of graphite phase carbon nitride in the $\mathrm{CN}$ spectrum, at about $13.0^{\circ}$ and $27.8^{\circ}$, corresponding to the in-plane tri-s-triazine motifs packing of $\mathrm{CN}$ and the interlayer of conjugated aromatic segments, respectively ${ }^{20}$. Due to the weak strength and low $\mathrm{V}_{2} \mathrm{C}$ content, the (0002) crystal plane of $\mathrm{V}_{2} \mathrm{C}$ is not observed in the $\mathrm{V}_{2} \mathrm{C} / \mathrm{CN}$ composite, but other 
characteristic peaks of $\mathrm{V}_{2} \mathrm{C}$ and $\mathrm{CN}$ can be clearly found on the spectrum. It shows the successful synthesis of $\mathrm{V}_{2} \mathrm{C} / \mathrm{CN}$.

\subsection{TG}

As shown in Fig. 4, the thermogravimetric curves of $\mathrm{V}_{2} \mathrm{C}, \mathrm{CN}$, and $\mathrm{CV}-3$ from $25^{\circ} \mathrm{C}$ to $800^{\circ} \mathrm{C}$ in a nitrogen atmosphere were characterized. The results showed that the weight loss rate of the catalyst decreases in

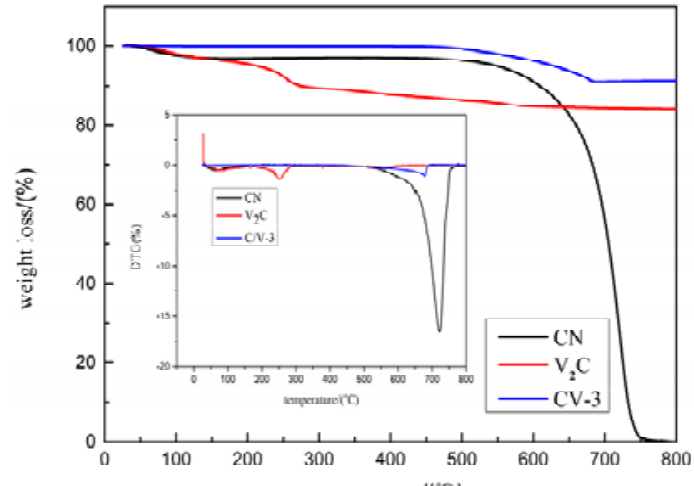

Fig. 4 TGA curves of V2C, CN, and CV-3 composite the following sequence: $\mathrm{CN} \quad(100 \%)>\mathrm{V} 2 \mathrm{C}$ $(15.97 \%)>C V-3 \quad(8.85 \%)$. It can be seen that the thermal stability of $\mathrm{CV}-3$ is much higher than that of $\mathrm{CN}$ and $\mathrm{V}_{2} \mathrm{C}$. The thermal decomposition process of $\mathrm{V}_{2} \mathrm{C}$ is divided into two stages. The first stage occurred at $280^{\circ} \mathrm{C}$. Most of the decomposition is attributed to the loss of crystalline water and water adsorbed by the stream. The second stage is from about $300^{\circ} \mathrm{C}$ to $800^{\circ} \mathrm{C}$. ${ }^{\circ} \mathrm{C}$, due to the loss of $\mathrm{OH} / \mathrm{O} / \mathrm{F}$ functional groups, in this process, $\mathrm{OH} / \mathrm{O} / \mathrm{F}$ is released in the form of $\mathrm{H}_{2} \mathrm{O}, \mathrm{O}_{2}, \mathrm{HF}^{16}$. $\mathrm{CN}$ was decomposed once at about $550^{\circ} \mathrm{C}$ to $750^{\circ} \mathrm{C}$. At this time, the structure of $\mathrm{CN}$ was completely destroyed and $\mathrm{CN}$ was completely decomposed $^{21}$. The thermal decomposition

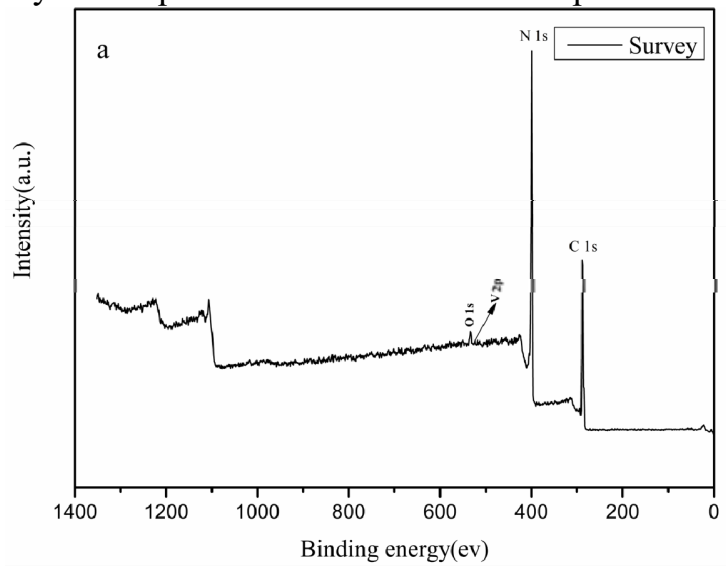

Fig. 5 (a) XPS survey spectra and high-resolution XPS spectra of (b) O1s; (c)
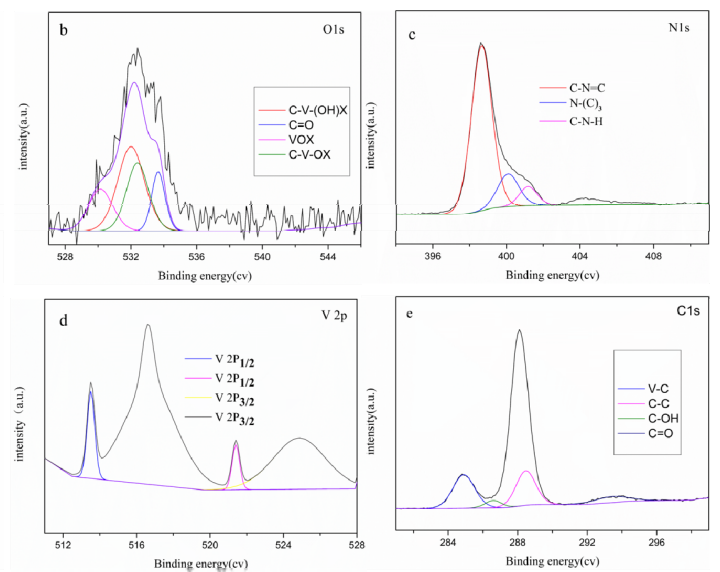

XPS was used to analyze the surface atomic composition and valence of $\mathrm{C} / \mathrm{V}-3$. The measured energy spectrum of C/V-3 clearly shows that the synthesized composite material contains $\mathrm{V}, \mathrm{N}, \mathrm{O}$ and $\mathrm{C}$ elements (Fig. 5(a)), indicating the formation of $\mathrm{V}_{2} \mathrm{C} / \mathrm{CN}$ phase. By analyzing the $\mathrm{N}$ 1s peak (Fig. 5(c)), it was determined that the binding energies of $\mathrm{N} 1 \mathrm{~s}$ were $398.67 \mathrm{eV}$ and $400.20 \mathrm{eV}$, 401.30ev, respectively. which can be attributed to $\mathrm{C}-\mathrm{N}=\mathrm{C}$, $\mathrm{N}-(\mathrm{C})_{3}, \mathrm{C}-\mathrm{N}-\mathrm{H}^{20}$. For O 1s (Fig5. (b)), the observed peak can be decomposed into four components, including $\mathrm{C}-\mathrm{V}-\mathrm{OH}_{\mathrm{x}}(532.01 \quad \mathrm{eV}), \quad \mathrm{C}-\mathrm{V}-\mathrm{O}_{\mathrm{x}} \quad(532.40$ $\mathrm{eV}), \mathrm{C}=\mathrm{O}(533.66 \mathrm{ev})$ and $\mathrm{VO}_{\mathrm{x}}(530.15 \mathrm{eV})^{21}$. The deconvoluted V 2p (Fig5. (d)) shows V 2p1/2 at 513.51 $\mathrm{eV}$ and $\mathrm{V} 2 \mathrm{p} 3 / 2$ at $521.41 \mathrm{eV}$, indicating the presence of $\mathrm{V}^{2+}$, which can be attributed to the remaining unreacted MAX phase in the prepared MXene and the same binding energy the overlap of the lower $\mathrm{V}-\mathrm{C}$ peak. $\mathrm{V}$ $2 \mathrm{p} 1 / 2$ at $516.62 \mathrm{eV}$ and $\mathrm{V} 2 \mathrm{p} 3 / 2$ at $524.86 \mathrm{eV}$ correspond to $\mathrm{V}^{4+}$ and $\mathrm{VO}_{2}(\mathrm{P})$ of $\mathrm{V}_{2} \mathrm{C}$, respectively ${ }^{19}$. The $\mathrm{C} 1 \mathrm{~s}$ area (Fig5. (e)) shows the existence of $\mathrm{V}-\mathrm{C}(284.89 \mathrm{eV}), \mathrm{C}-\mathrm{C}$ (288.47eV), C-OH (286.60 eV) and $\mathrm{C}=\mathrm{O}(293.43 \mathrm{eV})$. XPS analysis results further prove that $\mathrm{V}_{2} \mathrm{C}$ has been successfully compounded on the $\mathrm{CN}$ substrate.

formation of by-products, the by-products gradually blocked the reaction sites of the catalyst, and the denitration performance began to slowly decrease and finally reached an equilibrium value. The results show that the $\mathrm{V}_{2} \mathrm{C} / \mathrm{CN}-\mathrm{NTP}$ system has better denitration performance than the single NTP system (28.1\%), the 
CN-NTP system $(35.2 \%)$ and the $\mathrm{V}_{2} \mathrm{C}-\mathrm{NTP}$ system (60.6\%). Among them, the $\mathrm{V}_{2} \mathrm{C} / \mathrm{CN}-\mathrm{NTP}$ system showed the best denitration performance, which was 2.1 and 1.2 times that of the CN-NTP system and the $\mathrm{V}_{2} \mathrm{C}$-NTP system, respectively. Therefore, it also proved that there is a synergistic effect between $\mathrm{V}_{2} \mathrm{C} / \mathrm{CN}$ and NTP (as shown in the Fig. 6).
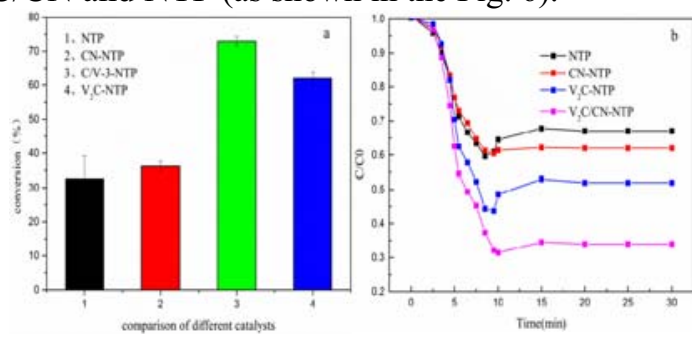

Fig. 6(a)Removal of NO with different treatment process. Conditions: simulated flue gas $2 / \mathrm{O} 2 / \mathrm{NO}=72 \% / 8 \% / 20 \%$

(b) Comparison of $\mathrm{V}_{2} \mathrm{C} 、 \mathrm{CN}$ and $\mathrm{CV}-3$ coupled NTP removal NO efficiency

\subsection{BET}

As shown in the Fig. 7, the specific surface area and pore structure of $\mathrm{g}_{-} \mathrm{C}_{3} \mathrm{~N}_{4}, \mathrm{~V}_{2} \mathrm{C}$ and $\mathrm{C} / \mathrm{V}-3$ composite materials were studied by the $\mathrm{N} 2$ adsorption-desorption analysis method. Although the three samples have type IV isotherms with $\mathrm{H} 3$ hysteresis loops, verifying the existence of the mesoporous structure, their specific surface area and pore volume are relatively low (as shown in the table. 1). A sharp peak from 2 to $20 \mathrm{~nm}$ is observed in the pore size distribution curve (as shown in

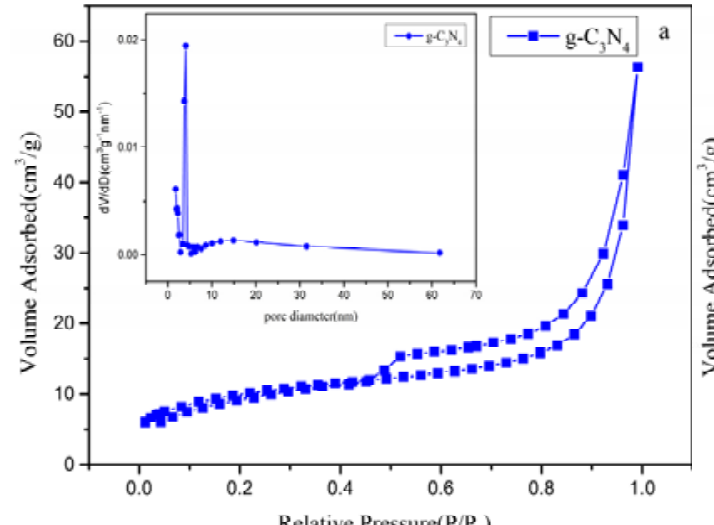

the figure $7(\mathrm{a})$ ).This indicates that $\mathrm{g}-\mathrm{C}_{3} \mathrm{~N}_{4}$ has a relatively uniform pore distribution and mesoporous characteristics ${ }^{20}$. Interestingly, the specific surface area of the binary $\mathrm{C} / \mathrm{V}-3$ composite material and the pore volume is higher than that of a single $\mathrm{CN}$ and $\mathrm{V}_{2} \mathrm{C}$. This may be due to the formation of $\mathrm{CN}$ between the $\mathrm{V} 2 \mathrm{C}$ layers that will expand the V2C layers and increase the BET specific surface area and pore volume. The high specific surface area can provide abundant active reaction sites. And promote more NO molecules to be adsorbed on its surface $^{22}$. Therefore, it can be concluded that compared with a single sample, the specific surface area helps to improve the photocatalytic activity, but it is not the key to improving the photocatalytic efficiency of the system Factors. As shown in the table.1,

Table. 1 Textural Properties of $\mathrm{V}_{2} \mathrm{C}, \mathrm{g}-\mathrm{C}_{3} \mathrm{~N}_{4}$, and C/V-3

\begin{tabular}{|l|l|l|}
\hline sample & $\mathrm{S}_{\mathrm{BET}}\left(\mathrm{m}^{2} \mathrm{~g}^{-1}\right)$ & $\mathrm{V}_{\text {total }}\left(\mathrm{cm}^{3} \mathrm{~g}^{-1}\right)$ \\
\hline $\mathrm{V}_{2} \mathrm{C}$ & 5.1890 & 0.04 \\
\hline $\mathrm{g}_{-} \mathrm{C}_{3} \mathrm{~N}_{4}$ & 34.2663 & 0.087 \\
\hline $\mathrm{C} / \mathrm{V}-3$ & 44.6565 & 0.25 \\
\hline
\end{tabular}

Compared with the pure $\mathrm{CN}$ sample, the SBET of $\mathrm{C} / \mathrm{V}-3$ increased by $39.4675 \mathrm{~m}^{2} \mathrm{~g}^{-1}$ and $\mathrm{V}_{\text {total }}$ increased by $0.21 \mathrm{~cm}^{2} / \mathrm{g}^{-1}$, which indicates that the large $\mathrm{S}_{\mathrm{BET}}$ and excellent adsorption performance of the composite are due to g-C3N4. In general, the adsorption capacity of the catalyst is significantly improved. The improved NO adsorption function can promote the photocatalytic oxidation process ${ }^{23}$.
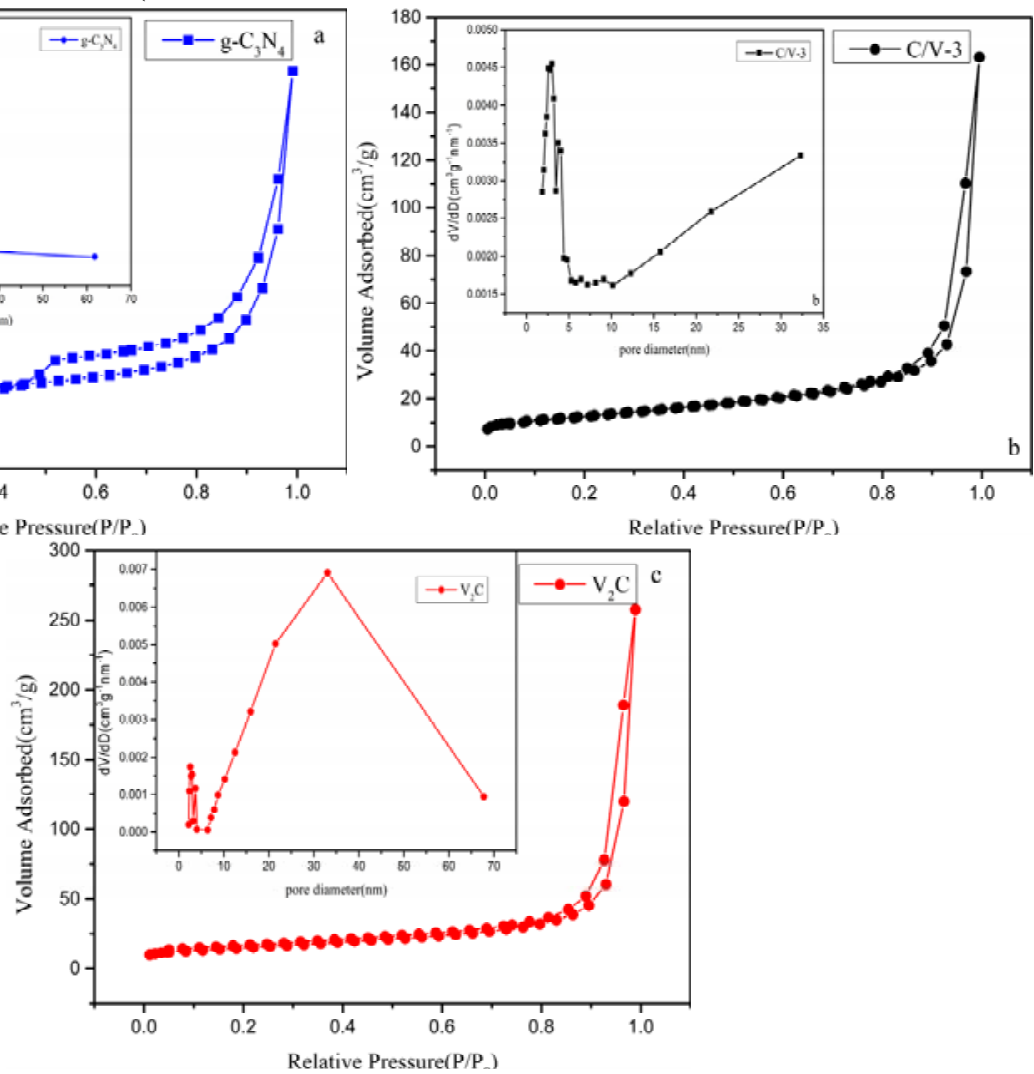

Fig. $7 \mathrm{~N}_{2}$ adsorption-desorption isotherm of (a)g- $\mathrm{C}_{3} \mathrm{~N}_{4}$; (b) C/V-3; and (c) $\mathrm{V}_{2} \mathrm{C}$ and corresponding BJH PSD curves(inset) 


\section{Mechanism analysis}

As shown in the fig.8, the mechanism of the $\mathrm{V}_{2} \mathrm{C} / \mathrm{g}-\mathrm{C}_{3} \mathrm{~N}_{4}-\mathrm{NTP}$ synergistic effect was studied. The high-energy electrons generated by the plasma convert $\mathrm{N}_{2}$ into $\mathrm{N}^{*}$ and adsorbed $\mathrm{N}_{2}$ (eq 2). In addition, due to the active groups generated during the discharge process, g- $\mathrm{C}_{3} \mathrm{~N}_{4}$ is excited, and the electrons in the valence band position of $\mathrm{g}-\mathrm{C}_{3} \mathrm{~N}_{4}$ are excited to conduction. The electrons in the conduction band of $\mathrm{g}-\mathrm{C}_{3} \mathrm{~N}_{4}$ are transferred to the valence band of $\mathrm{V}_{2} \mathrm{C}$ due to the built-in electric field, and the holes are formed in the valence band, which significantly enhances the separation of electrons and holes ${ }^{24}$. Part of the high-energy electrons can also be injected into the conduction band of $\mathrm{g}-\mathrm{C}_{3} \mathrm{~N}_{4}$ by hitting its surface. The electrons and injected electrons participate in the conversion process of $\mathrm{NO}$ adsorbed on the surface of the $\mathrm{g}_{-} \mathrm{C}_{3} \mathrm{~N}_{4}$ catalyst. Finally, $\mathrm{NO}$ is reduced to produce $\mathrm{N}_{2}$ and $\mathrm{O}_{2}$ (eqs 3-5). At the same time, the $\mathrm{O}^{*}$ and $\mathrm{O}_{3}$ produced during the reaction oxidize $\mathrm{NO}$ to intermediate product $\mathrm{NO}_{2}(\mathrm{eq} 6)$, and then $\mathrm{NO}_{2}$ reacts with $\mathrm{N}^{*}$ to be reduced to $\mathrm{N}_{2}$ and $\mathrm{O}_{2}$ (eqs 7-11). Therefore, the high-energy electric field generated by the plasma can also effectively separate electrons and holes. In return, the $\mathrm{g}-\mathrm{C}_{3} \mathrm{~N}_{4}$ catalyst changed the discharge method and made the discharge more uniform. This synergistic effect improved the NO conversion rate and energy efficiency ${ }^{10}$.

$$
\begin{aligned}
& \mathrm{V}-\mathrm{CN}-3+\text { plasma } \rightarrow \mathrm{V}_{2} \mathrm{C}\left(\mathrm{e}^{-}\right)+\mathrm{g}-\mathrm{C}_{3} \mathrm{~N}_{4}\left(\mathrm{~h}^{+}\right) \\
& \mathrm{N}_{2}+\mathrm{e}^{-}(\mathrm{p}) \rightarrow \mathrm{N}+\mathrm{N}+\mathrm{e}^{-}(\mathrm{p}) \\
& \mathrm{NO}+\mathrm{N} \rightarrow \mathrm{N}_{2}+\mathrm{O} \\
& \mathrm{O}_{2}+\mathrm{e}^{-}(\mathrm{p}) \rightarrow \mathrm{O}+\mathrm{O}+\mathrm{e}^{-}(\mathrm{p}) \\
& \mathrm{O}_{2}+\mathrm{O} \rightarrow \mathrm{O}_{3} \\
& \mathrm{NO}+\mathrm{O} \rightarrow \mathrm{NO}_{2} \\
& \mathrm{NO}+\mathrm{O}_{3} \rightarrow \mathrm{NO}_{2}+\mathrm{O}_{2} \\
& \mathrm{~N}_{2}+\mathrm{e}^{-} \rightarrow \mathrm{e}^{-}+\mathrm{N}_{2}(\mathrm{~A}) \\
& \mathrm{N}_{2}(\mathrm{~A})+\mathrm{NO} \rightarrow \mathrm{N}_{2}+\mathrm{N}+\mathrm{O} \\
& \mathrm{N}_{2}(\mathrm{~A})+\mathrm{N}_{2} \mathrm{O} \rightarrow 2 \mathrm{~N}_{2}+\mathrm{O} \\
& \mathrm{NO}_{2}+\mathrm{N} \rightarrow \mathrm{N}_{2}+\mathrm{O}_{2}
\end{aligned}
$$
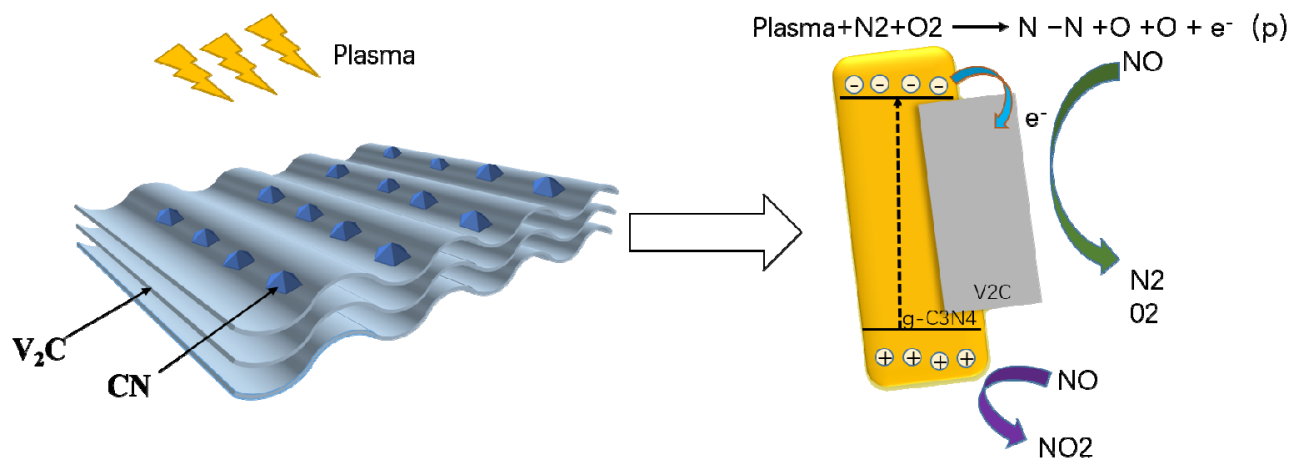

Fig. 8 Reaction mechanism

\section{Conclusions}

In this work, a new g-C3N4/V2C MXene catalyst has been successfully synthesized, and used for plasma denitration technology for the first time. The optimized composite $\mathrm{C} / \mathrm{V}-3$ showed an improved NO removal of $83.3 \%$ in the high-energy electric field, which is 1.2 and 2.1 times higher than $\mathrm{V}_{2} \mathrm{C}-\mathrm{NTP}$ and $\mathrm{g}-\mathrm{C}_{3} \mathrm{~N}_{4}-\mathrm{NTP}$ systems alone, respectively. The electrons transferred to $\mathrm{V} 2 \mathrm{C}$ and the injected electrons react with the generated active 
groups to reduce $\mathrm{NO}$ to $\mathrm{N} 2$ and $\mathrm{O} 2 . \mathrm{G}-\mathrm{C}_{3} \mathrm{~N}_{4}$ can be excited by high-energy electric field and then can transfer electrons to $\mathrm{V}_{2} \mathrm{C}$ MXene which facilitates the separation of electron-hole pairs. The synergistic effects of catalysts-plasma system promoted the transfer of electrons. The results of this study reveal the significant potential of $\mathrm{V}_{2} \mathrm{C}$ MXene for application in the denitration technology field.

\section{References}

1. Fan, W.; Chan, K. Y.; Zhang, C.; Zhang, K.; Ning, Z.; Leung, M. K. H., A feasibility study 225, 535-541(2018).

2. Li, X.; Zhang, C.; Zhang, X.; Li, W.; Tan, P.; Ma, L.; Fang, Q.; Chen, G., Chemical Engineering Journal 335, 483-490(2018).

3. Wang, T.; Zhang, X.; Liu, J.; Liu, H.; Wang, Y.; Sun, B., Applied Thermal Engineering 130, 1224-1232(2018).

4. Yu, Q.; Wang, H.; Liu, T.; Xiao, L.; Jiang, X.; Zheng, X., Environmental science \& technology 46, 2337-44(2012).

5. Majdoub, M.; Anfar, Z.; Amedlous, A., ACS Nano 14 (10), 12390-12469(2020).

6. Liao, J.; Cui, W.; Li, J.; Sheng, J.; Wang, H.; Dong, X. a.; Chen, P.; Jiang, G.; Wang, Z.; Dong, F., Chemical Engineering Journal 379, 122282(2020).

7. Wu, S.; Yu, H.; Chen, S.; Quan, X., ACS Catalysis 10 (24), 14380-14389(2020).

8. Xing, Y.; Yin, L.; Zhao, Y.; Du, Z.; Tan, H.-Q.; Qin, X.; Ho, W.; Qiu, T.; Li, Y.-G., ACS Applied Materials \& Interfaces 12 (46), 51555-51562(2020).

9. Lu, N.; Bao, X.; Jiang, N.; Shang, K.; Li, J.; Wu, Y., Topics in Catalysis 60 (12), 855-868(2017).

10. Lu, N.; Sun, D.; Zhang, C.; Jiang, N.; Shang, K.; Bao, X.; Li, J.; Wu, Y., Journal of Physics D: Applied Physics 51 (9), 094001(2018).
11. Naguib, M.; Kurtoglu, M.; Presser, V.; Lu, J.; Niu, J.; Heon, M.; Hultman, L.; Gogotsi, Y.; Barsoum, M. W., 23 (37), 4248-4253(2011).

12. Zhu, J.; Ha, E.; Zhao, G.; Zhou, Y.; Huang, D.; Yue, G.; Hu, L.; Sun, N.; Wang, Y.; Lee, L. Y. S.; Xu, C.; Wong, K.-Y.; Astruc, D.; Zhao, P., Coordination Chemistry Reviews 352, 306-327(2017).

13. Zhang, Y.; Wang, L.; Zhang, N.; Zhou, Z., RSC Advances 8 (36), 19895-19905(2018).

14. Sinha, A.; Dhanjai; Zhao, H.; Huang, Y.; Lu, X.; Chen, J.; Jain, R., TrAC Trends in Analytical Chemistry 105, 424-435(2018).

15. Huang, D.; Xie, Y.; Lu, D.; Wang, Z.; Wang, J.; Yu, H.; Zhang, H., 31 (24), 1901117(2019).

16. Wu, M.; Wang, B.; Hu, Q.; Wang, L.; Zhou, A., 11 (11), 2112(2018).

17. Wu, X.; Wang, H.; Zhao, Z.; Huang, B., Journal of Materials Chemistry A 8 (25), 12705-12715(2020).

18. Liu, F.; Liu, Y.; Zhao, X.; Liu, K.; Yin, H.; Fan, L. Z., Small 16 (8), e1906076(2020).

19. Wang, Z.; Yu, K.; Feng, Y.; Qi, R.; Ren, J.; Zhu, Z., ACS Applied Materials \& Interfaces 11 (47), 44282-44292(2019).

20. Liu, Q.; Chen, C.; Yuan, K.; Sewell, C. D.; Zhang, Z.; Fang, X.; Lin, Z., Nano Energy 77, 105104(2020).

21. Yao, C.; Wang, R.; Wang, Z.; Lei, H.; Dong, X.; He, C., Journal of Materials Chemistry A 7 (48), 27547-27559(2019).

22. Di, J.; Xia, J.; Ji, M.; Wang, B.; Yin, S.; Zhang, Q.; Chen, Z.; Li, H., Applied Catalysis B: Environmental 183, 254-262(2016).

23. Wang, H.; Zhao, R.; Qin, J.; Hu, H.; Fan, X.; Cao, X.; Wang, D., ACS Applied Materials \& Interfaces 11 (47), 44249-44262(2019).

24. Tang, Q.; Sun, Z.; Deng, S.; Wang, H.; Wu, Z., Journal of Colloid and Interface Science 564, 406-417(2020). 